\title{
Analysis of Microbial Air Quality in the Surrounding Hospital's Wastewater Treatment Plants in Jakarta, Indonesia
}

\author{
Gabriel Andari Kristanto ${ }^{1, *}$, and Fatma Nur Rosana ${ }^{1}$ \\ ${ }^{1}$ Department of Civil Engineering, Faculty of Engineering, Universitas Indonesia, Depok 16424, \\ Indonesia
}

\begin{abstract}
As hospitals require the usage of various hazardous drugs and chemicals in its daily operation, the often contaminated wastewater of health facilities needs to be processed to comply with the quality standards specified in Regulation of the Governor of DKI Jakarta No. 65/2013. However, wastewater treatment plants (WWTP) can also pollute not only water but also the ambient air of facilities. The objective of this research is to identify airborne bacteria and the concentration of fungi due to the presence of WTP and to analyse the types of bacteria that exist through Gram Staining. Microbial air samples taken using EMS E6 showed that the average concentration of bioaerosol at hospital's WWTP was about 810$1,915 \mathrm{CFU} / \mathrm{m}^{3}$ for bacteria and $1,450-1,955 \mathrm{CFU} / \mathrm{m}^{3}$ for fungi. Furthermore, the highest concentration of bacteria and fungi found in the surrounding equalization and aeration tanks was $1,915 \mathrm{CFU} / \mathrm{m}^{3}$ and 1,955 $\mathrm{CFU} / \mathrm{m}^{3}$, respectively, which far exceeded the background value of 80 $\mathrm{CFU} / \mathrm{m}^{3}$ for bacteria and $440 \mathrm{CFU} / \mathrm{m}^{3}$ for fungi. Gram staining of the bacteria found in the air surrounding WWTP showed 94\% Gram-negative with the bacteria being pathogenic. Therefore, it is pertinent that further action is taken to prevent bioaerosol from spreading around WWTP by building better ventilation surrounding the plants, indicating the technology of the treatment plant to be used, and enforcing personal safety measures on WWTP's employees.
\end{abstract}

\section{Introduction}

Hospital wastewater contains pathogenic, toxic, degradable, and radioactive contaminants which have harmful effect on health [1]; thus, it requires treatment prior to the surface water discharge. The function of wastewater treatment plant (WWTP) is to eliminate the contaminants and pathogens in wastewater in order to prevent it from polluting the environment and harming people's health. Biological treatment process generally utilizes microorganism for degrading pollutant compound. However, it should be noted that the process in WWTP can also produce air pollution, known as bioaerosol. Bioaerosol is one type of air pollutant which contains microorganism and has the potential for affecting

\footnotetext{
*Corresponding author: gakristanto@gmail.com; andari@eng.ui.ac.id
} 
human health in the forms of infectious diseases, allergies, and cancer [2]. Bioaerosol can be naturally produced in decomposition of organic matter by microbes dispersed to atmosphere. Furthermore, bioaerosol emission can be produced through human activities, and one of them is waste disposal facility including biological treatment plant, MBT (mechanical biological treatment) unit process, material recovery facilities and solid waste transfer station, landfill, and WWTP [3, 4, 5, 6, 7]. The microorganism contained in bioaerosol such as bacteria and fungi are commonly found in the surrounding WWTP [8, 9]. Bioaerosol in WWTP comes from bubbles generated from aeration process or oxygen from degradation process [10] which can be pathogenic and can cause allergy if inhaled thus making this bioaerosol existence highly influential in the quality of the ambient air [11]. The magnitude of this bioaerosol emission is influenced by factors such as WWTP capacity, applied treatment plant technology, applied treatment plant machines, applied treatment method, and content of contaminants in wastewater [10]. In addition, factors such as nutrients, humidity, temperature, and oxygen can affect the growth of microorganism [12]. The purpose of this research is to analyze: 1) the concentration of bacteria and fungi in WWT's ambient air; 2) the influence of temperature, humidity, and wind on WWTP's ambient air; and 3) the existence of pathogenic bacteria in air sample.

\section{Methodology}

\subsection{Sampling Location and Time}

Sampling took place at waste water treatment plant (WWTP) in Dr. Suyoto Rehabilitation Center of the Ministry of Defense and conducted in January and April 2016 in wet/rainy and dry seasons. The sampling points were on WWTP site as shown in Fig. 1. The distance of sampling from WWTP was $0,10,20,30,40$, and 50 meter(s), whereas background concentrations were obtained from the Faculty of Engineering, Universitas Indonesia, Depok and used as a comparison to identify the effect of WWTP's existence on air quality.

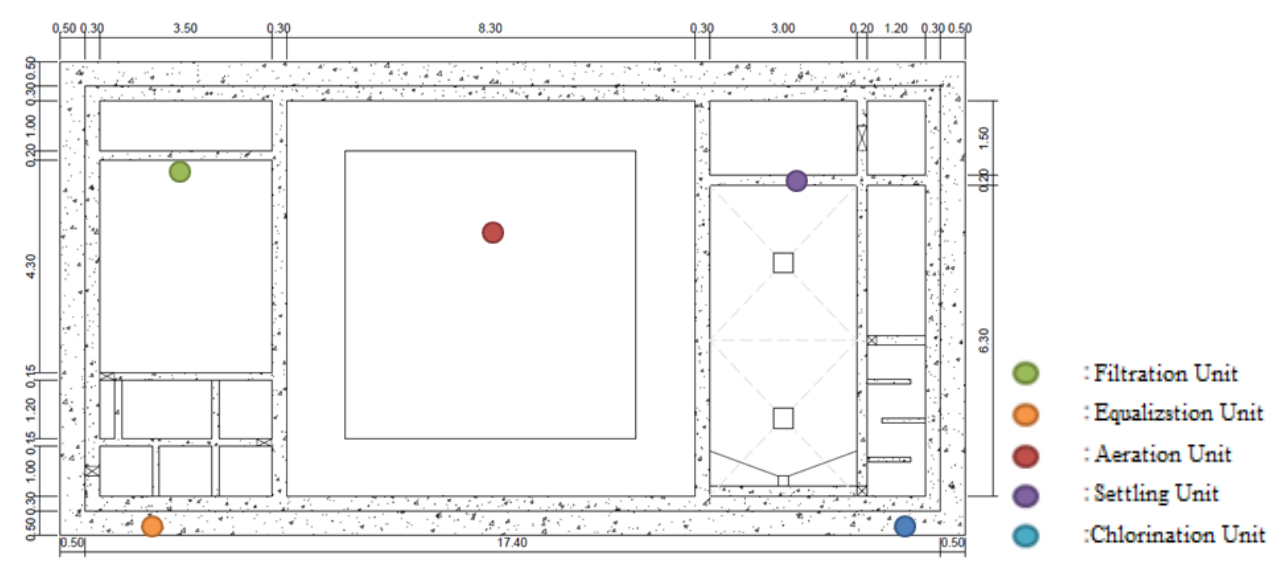

Fig. 1. Sampling Points 


\subsection{Parameters \& Method}

The sampling of bacteria and fungi was done using Single-Stage Multi Orifice Bioaerosol with a capacity of $25 \mathrm{~L} /$ minute vacuum pump. The measurement of air temperature, humidity, and wind velocity parameters used anemometer instrument of Lutron type AH4223. The agar medium used was Tryptic Soy Agar (Oxoid) as the medium for the growth of bacteria at incubation temperature of $37^{\circ} \mathrm{C}$ for 24 hours and Malt Extract Agar (Oxoid) as the medium for the growth of fungi at incubation temperature of $29^{\circ} \mathrm{C}$ for 72 hours. The counting of bacteria and fungi growing in the media was done using Total Plate Count (TPC) method. Gram staining was used to find out the Gram type of the bacteria which involved 4 dye solutions such as crystal violet, Lugol's iodine, alcohol, acetone, and safranin. The observation of bacteria was conducted using Olympus IX73 Research Inverted microscope with a magnification of 100 and Olympus DP73 Color-Monochrome Dual CCD 17.28 MP.

\subsection{Analysis of Data}

The average concentration of bacteria and fungi in $\mathrm{CFU} / \mathrm{m}^{3}$ (Colony Forming Unit/cubic meter) was calculated as follows:

$$
\text { Microorganism Concentration }=C F U / \text { Plate } \times \frac{1}{0.0250^{3} / \text { minute }} \times \frac{60^{s e c o n d} / \text { minute }}{t \text { second }}
$$

The impact of physical parameter on the concentration of bacteria and fungi was obtained statistically by employing correlation test with SPSS 16.0.

\section{Results and Discussion}

\subsection{Concentration of Bioaerosol in the Surrounding WWTP}

The sampling of bioaerosol in WWTP was conducted in wet season when it was drizzling and raining lightly. The data measurement of bioaerosol in WWTP showed varying results (Fig. 2.):

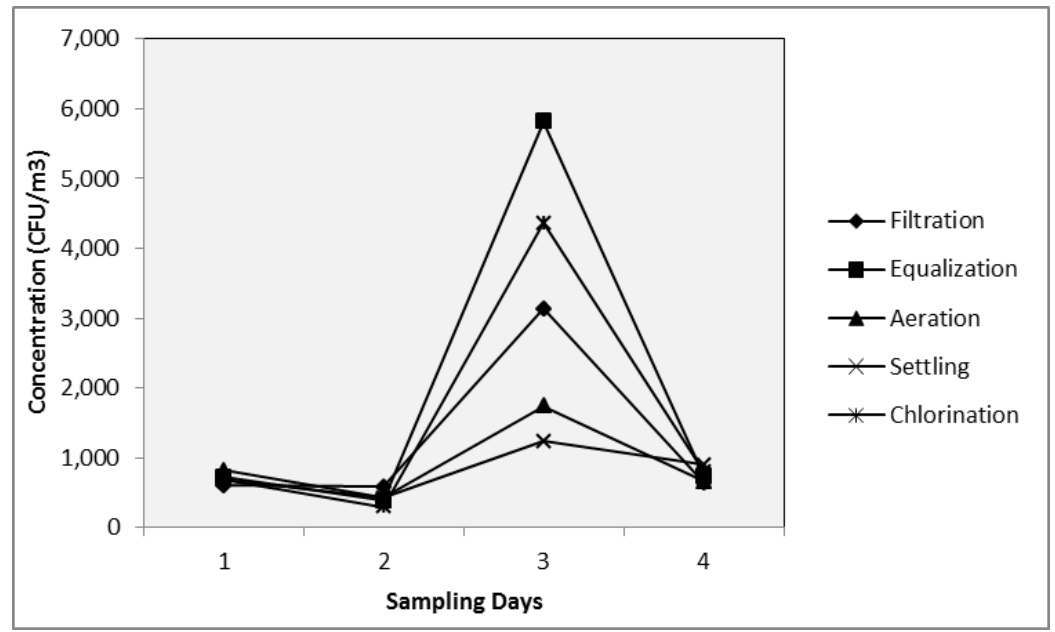

(a) 


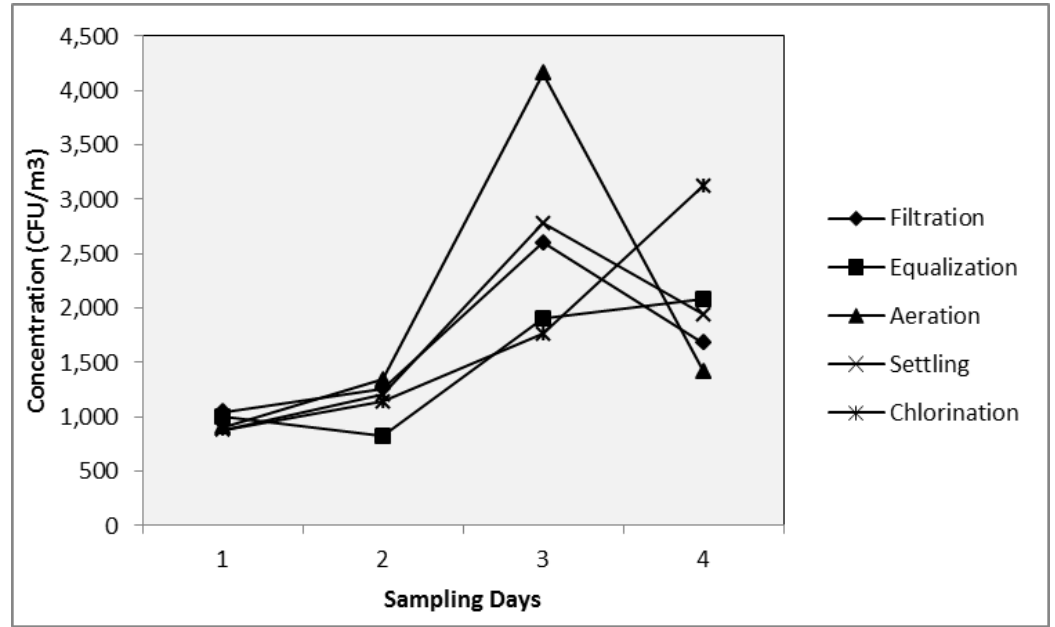

(b)

Fig. 2. (a) Bacteria and (b) Fungi Concentration in WWTP

It was found that the concentration of bacteria and fungi was higher during rainy days due to higher air humidity. According to a research, the concentration of bioaerosol in bacteria and fungi during rainy season will be three to seven times higher than that of in normal dry (not raining) condition [13]. As for this research, the average concentration of bioaerosol in bacteria increased three to fifteen times during the rainy season and two to five times in fungi during the dry season. Therefore, seasonal factor can also affect the concentration of bioaerosol in bacteria and fungi.

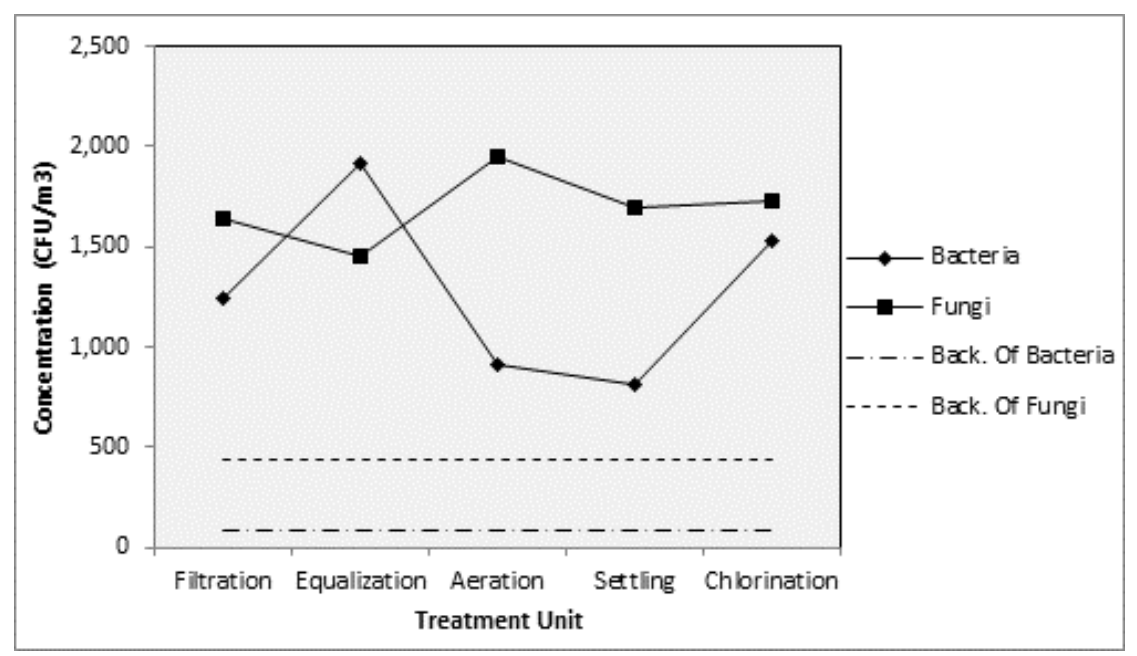

Fig. 3. Average Concentration of Bioaerosol in WWTP

As illustrated in Fig. 3, the concentration of bacteria and fungi in WWTP have exceeded the background concentration which means WWTP can be a factor in the increased concentration of bioaerosol in the surrounding area. The highest concentration of bacteria in equalization unit was $1,915 \mathrm{CFU} / \mathrm{m}^{3}$, while the highest concentration of fungi in aeration unit was $1,955 \mathrm{CFU} / \mathrm{m}^{3}$. This high concentration in equalization unit indicated the 
utilization of microorganism used in wastewater treatment plant to reduce organic pollutants in wastewater. This finding was supported by the fact that equalization unit functions as biological treatment involving microorganism. A research showed that oxidation ditch produced the highest microbe aerosol in domestic WWTP in China [14]. Like the previous research, shows that the highest mesophilic bacteria are produced in trickling filter unit in domestic WWTP in Italy [15]. Similarly, one hospital in Jakarta, Indonesia, shows that hospital's WWTP can also be the source of bioaerosol pollution, and the highest concentration of bacteria is found in aeration unit (Integrated WWTP 1) and equalization unit (Integrated WWTP 2), while the highest concentration of fungi is found in equalization unit (Integrated WWTP 1) and in sedimentation unit (Integrated WWTP 2) [16]. The aeration using diffusors can increase the concentration of bioaerosol in the air through the bursting of water bubbles that releases microorganism. The bubbles formed from aeration process contain microorganism in high concentration, and through the research, aeration unit become the main source of bioaerosol [17].

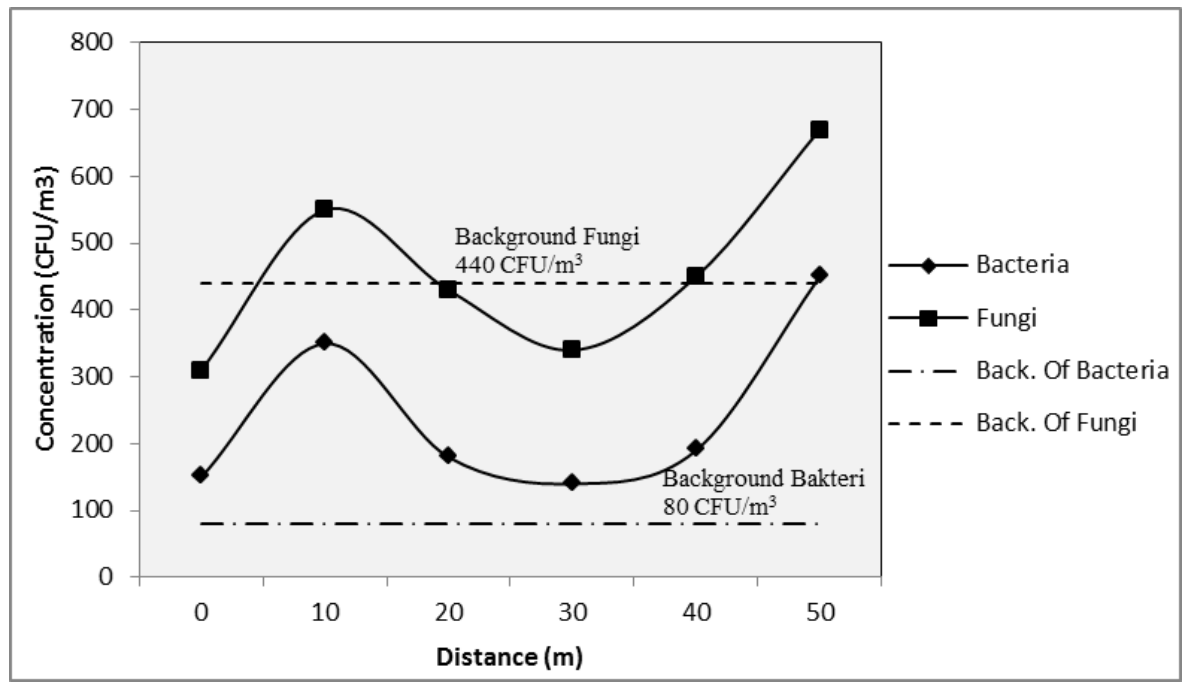

Fig. 4. Bioaerosol according to distance variance

Apart from that, environmental factor can also promote the growth and distribution of microorganism in air. The distribution of bioaerosol in WWTP is shown in the concentration of bioaerosol to distance as illustrated in Fig. 4. The samples were taken in dry season, when it was sunny. The concentration of bioaerosol varied at a distance of every $0-50$ meter(s), and this concentration of bacteria exceeded the threshold limit allowed by the Ministry. On the other hand, the concentration of fungi at a distance of 0 , 20, and 30 meter(s) although it was still below the limit. When sampling was conducted, the aeration unit was not in operation hence the concentration of bioaerosol at 0 meter from WWTP was lower than the 10 meter(s) sampling point. Apart from that, the high temperature and low humidity can lower bioaerosol concentration. At a2 distance of 10 and 50 meter(s) the concentration of both bacteria and fungi showed an increase, which could be caused by the factors of sampling location and environment such as temperature and humidity. Another increase was shown at a distance of 40 and 50 meter(s), which may be caused by other sources of bioaerosol in the physiotherapy room. There was a decrease in the concentration of bioaerosol at a distance of 20 and 30 meter(s) influenced by factors such as the distance to WWTP, wind velocity, and even the altitude of the location may also cause a faster distribution of bioaerosol in the air. 
In terms of variance in seasonal condition between the rainy and the dry season, the concentrations in rainy season are higher than that of in dry season. To prevent this difference, the observed point was the aeration point where the sampling location for both seasons took place at a distance of 0 meter. The concentrations of bacteria during the rainy season are $400-2,800 \mathrm{CFU} / \mathrm{m}^{3}$ and the fungi concentrations are $840-4,520 \mathrm{CFU} / \mathrm{m}^{3}$, while during the dry season the concentration of bacteria and fungi was around $100-200$ $\mathrm{CFU} / \mathrm{m}^{3}$ and $240-380 \mathrm{CFU} / \mathrm{m}^{3}$ respectively. These results showed that the concentrations of bioaerosol in dry season are lower than in rainy season. Statistical correlation shows that there is a significant relation between temperature and humidity in the air toward the concentration of bioaerosol. The moderately high temperature can affect the growth of microorganism due to the tendency of bacteria to die in high temperature, while the moderately high humidity will support the growth of microorganism. Moreover, WWTP's condition can also have effect on the concentration of bioaerosol when bioaerosol may be from the bubbles produced by aeration process or the oxygen produced by degradation process [10], may be pathogenic and develop allergy if inhaled [11]. When the samplings took place in dry season, no aeration occurred, and this caused lower bioaerosol emission.

\subsection{Correlation of Physical Properties with the Concentration of Bioaerosol}

Microorganisms can grow and develop in certain temperature and humidity; in other words, there are necessary conditions for them to live. If the environment is below the optimum level, it will hamper their growth; conversely, if it is above the optimum level, it will make them lethal. Furthermore, microorganisms also have a certain life expectancy and are only likely to survive in a relatively short time.

Table 1. Physical Parameter Influence on the Concentration of Bioaerosol

\begin{tabular}{|c|c|c|c|}
\hline & Air Temperature & Air Humidity & Wind Velocity \\
\hline Bacteria concentration & $-0.314^{*}$ & $0.401^{* *}$ & $-0.303^{*}$ \\
\hline Fungi concentration & 0.063 & $0.570^{* *}$ & 0.140 \\
\hline
\end{tabular}

Signification: $* P$ value $<0,05$ and $* * P$ value $<0,01$

$\mathrm{N}: 64$

Table 1 shows the correlation between physical parameters, such as air temperature, air humidity, and wind velocity and the concentration of bacteria and fungi. There is a significant correlation between these parameters and bacteria concentration ( $P$ value $=$ $0.012 ; P$ value $=0.001 ; P$ value $=0.015$ respectively $)$ and as for fungi concentration, there is only significant correlation with air humidity $(P$ value $=0.000)$. Air humidity has the highest correlation with both the concentration of bacteria and fungi indicating that air humidity can influence bioaerosol concentration (the higher the humidity, the higher the concentration of bioaerosol). On the other hand, it does not have any significant correlation with fungi concentration. The correlation of air temperature and humidity with that of bioaerosol can be overlooked in the measurement results in both rainy and dry season. It is shown by the existence of bioaerosol in a lower concentration when the temperature is high in dry season and higher bioaerosol concentration will occur if humidity in wet season is high. Air temperature and wind velocity have a moderately significant correlation with fungi concentration [18].

\subsection{Identification of Gram-positive and Gram-negative Bacteria}

The majority of bacteria in WWTP are Gram-negative bacteria making up about $94 \%$ of the population, whereas the remain $6 \%$ are Gram-positive bacteria. The shapes of the observed 
bacteria are rod and coccus, yet the most observed bacteria are the rod-shaped ones which vary in size from 0.73 to $11.04 \mu \mathrm{m}$. These bioaerosols have the ability to give impacts on living things in the forms of infectivity, allergy, toxicity, pharmacology, or other processes [19]. Fig. 5 shows the result of Gram staining for Gram-negative and Gram-positive bacteria.

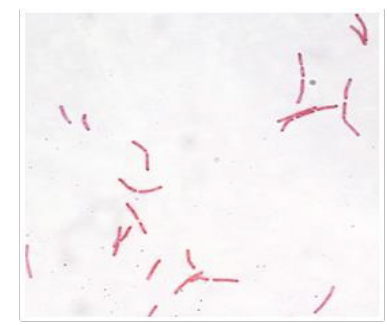

(a)

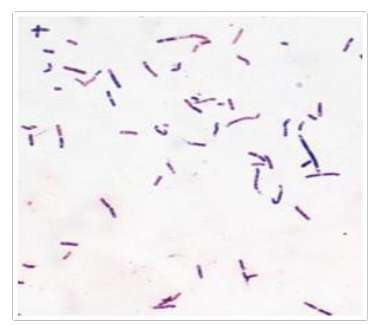

(c)

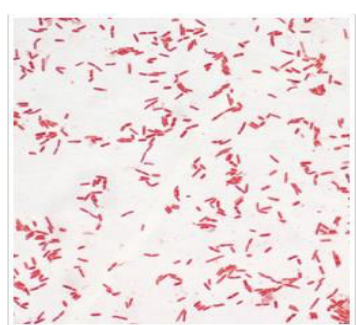

(b)

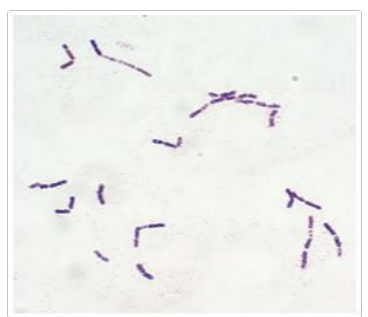

(d)

Fig. 5. (a) and (b) Gram Negative Bacteria; (c) and (d) Gram Positive Bacteria

\section{Conclusion}

The average concentration of bioaerosol surrounding the WWTP was around $810-1,915$ $\mathrm{CFU} / \mathrm{m}^{3}$ for bacteria and $1,450-1,955 \mathrm{CFU} / \mathrm{m}^{3}$ for fungi. The highest concentration of bacteria and fungi was $1,915 \mathrm{CFU} / \mathrm{m}^{3}$ in equalization unit, whereas the second highest was $1,955 \mathrm{CFU} / \mathrm{m}^{3}$ in the aeration unit. There was a moderately strong correlation between air humidity and the concentration of bacteria and fungi. This correlation can be overlooked in research result showing high air humidity and an increased concentration of bacteria or fungi. The factor of aeration system used in wastewater treatment was also able to increase the concentration of bioaerosol in the air. The bacteria produced in WWTP showed that $94 \%$ of them were gram negative and predominantly rod-shaped in highly varying size from 0.73 to $11.04 \mu \mathrm{m}$.

\section{References}

1. Prayitno, Z. Kusuma, B. Yanuwiadi, R.W. Laksmono, Res. Inv.: Int. J. of Eng. and Sc. 2, 13-16 (2013)

2. J. Douwes, P. Thorne, N. Pearce, D. Heederik, Ann. Occup. Hyg. 47, 187-200 (2003)

3. V. Kummer, W.R. Thiel, Int. J. of Hyg. and Env. Health, 35, 299-307 (2008)

4. G.A. Kristanto, E. Novita, Yudithia, World App. Sc. J. 33, 453-459 (2015)

5. L. Pascual, S. Pérez-Luz, M.A. Yáñez, A. Santamaría, K. Gibert, M. Salgot, D. Apraiz, V. Catalán, Aerobiologia. 19, 261-270 (2003)

6. M.A. Sánchez-Monedero, M.I. Aguilar, R. Fenoll, A. Roig, Water Res. 42. 3739-3744 (2008) 
7. K. Kruczalak, K. Olańczuk-Neyman, Pol. J. of Env. Stu. 13. 537-542 (2004)

8. V.M. Cavinatto. Influency of Environmental Factors in the Dispersion of Particles Originated in a System of Biological Treatment of Sewage in Vals of Oxidation (Universidade de São Paulo, São Paulo, 1991)

9. M.D. Azevedo, M.A.Couto, S.G. Leite, B.R. Azevedo, P.A. Almeida, A.S. Procópio, et al., Int. J. of Eng. \& Tech. IJET-IJENS. 14, 48-55 (2014)

10. M. Vítězová, T. Vítěz, H. Mlejnková, T. LošákActa Univ. Agr. et Silviculturae Mendelianae Brunensis, LX, 233-240 (2012)

11. N. Patentalakis, A. Pantidou, N. Kalogerakis, Water, Air, \& Soil Pollution: Focus. 8, 107-115 (2008)

12. L.M. Prescott, J.P. Harley, D.A. Klein, Microbiology, Seventh Ed. (McGraw-Hill, New York, 2008)

13. K.J. Heo, H.B. Kim, B.U. Lee, J. of Aerosol Sc. 77, 31-37 (2014)

14. Y. Li, H. Zhang, X. Qiu, Y. Zhang, H. Wang, Aerosol and Air Quality Research, 13, 1807-1814 (2013)

15. L. Fracchia, S. Pietronave, M. Rinaldi, M. Giovanna Martinotti, Water Res. 40, 19851994 (2006)

16. P.N. Sari, Effect of The Availability of Wastewater Treatment Plant on The Microbial Air Quality (A Case Study: Dr. Cipto Mangunkusumo Hospital) (Universitas Indonesia, Depok, 2013)

17. Z. Filipkowska, W. Janczukowic, M. Krzemieniewski, J. Pesta, Pol. J. of Env. Stud. 9, 273-280 (2000) (5)

18. S. Niazi, M.S. Hassanvand, A.H. Mahvi, R. Nabizadeh, M. Alimohammadi, S. Nabavi, et al., Env. Sc. and Poll. Research, 22, 16014-16021 (2015) (10)

19. C.S. Cox, C.M. Wathes, Bioaerosols Handbook (CRC Press, United States of America, 1995) 